\title{
Not yet written
}

It's midnight. You're washing dishes

for the third time today;

touching the sharp point of nothing.

A pathetic breeze leaks

through the window, crickets grate.

You've been watching TV all night.

Documentaries-death

Of the Koorong, the Exxon oil spill

and men who have sex

with blow-up dolls. Then

when you switch off,

you sit in the dark, head going

into noughts and crosses.

There is a world inside you.

It is over-populated, and

things are dire. Millions cry out

in tongues you cannot understand.

And so here you are,

sweating into the sink,

cleaning it all away. Later

you will go outside, with the air

hanging down on you like a wet towel.

You will throw your food scraps

on to the lawn. It will be gone

by morning, to God knows. 
And there you will stand.

In the outside lights, your shadow will cast many angles.

Do not be afraid. All we need is for you to give us the word.

Because no matter what you claim, or disown, a poem will be written and it will be in your hand.

Paul South 